\title{
A corporeidade na aprendizagem escolar (Entrelaços fenomenológicos do pensar e agir)
}

\section{Corporality in school learning (Tangles of phenomenological thinking and acting)}

\author{
Ernesto Candeias Martins ${ }^{1}$
}

\begin{abstract}
RESUMO
A corporeidade é o elemento de visibilidade dos embates do 'corpo' com o mundo, produzidos pelos efeitos histórico-culturais e pelas novas articulações propiciadoras de predisposições estratégicas dos corpos e das almas, resultantes das forças do saber e do poder, que permite sedimentar esses confrontos e dinamizar campos de verdades historicamente constituídos e em constante mudança. $\mathrm{O}$ autor questiona, nos andaimes antropológicos, sociológicos e pedagógicos, o sentido do 'corpo' e da 'corporeidade' no processo educativo, argumentando dois pontos fulcrais: a visão histórico-filosófica da semântica dos termos, insistindo nos discursos (elementos psicológicos relacionados com a identidade e imagem) sobre o corpo; a análise hermenêutica à 'corporeidade' em Merleau-Ponty e Zubiri; a análise educativa da relação da corporeidade e aprendizagem, na complexidade escolar atual.

Palavras-chave: corporeidade; filosofia do corpo; aprendizagem escolar; Merleau-Ponty; Zubiri.
\end{abstract}

\begin{abstract}
The body element is the visibility of the 'body' clashes with the world, produced by historical-cultural effects and the new generation of joint strategic predispositions of bodies and souls, resulting from the forces of knowledge and power, which allows to sediment these confrontations and to
\end{abstract}

DOI: $10.1590 / 0104-4060.40978$

1 Escola Superior de Educação. Instituto Politécnico de Castelo Branco. Castelo Branco, Portugal. Rua Prof. Faria de Vasconcelos.6000-262. E-mail: ernesto@ipcb.pt 
fuel historically established truths and fields in constant change. The author questions the anthropological, sociological and pedagogical scaffolding, the sense of 'body' and 'natural resources' in the educational process, arguing two key points: the historical-philosophical vision of the semantics of the terms, insisting on speeches (psychological elements related to identity and image) on the body; the hermeneutic analysis concerning 'embodiment' in Merleau-Ponty and Zubiri; the educational analysis of the relationship of corporality and learning, in the current school complexity.

Keywords: corporality; philosophy of the body; school learning; MerleauPonty; Zubiri.

\section{À guisa de introdução: umas quantas razões...}

A arquitetura da nossa argumentação conflui o pensamento, a ação e a vida, o corpo e a alma, o corpo e a corporeidade, ou seja, termos interpretados pela história e antropologia e articulados nos diferentes contextos discursivos e filosóficos. A alma constitui, seguindo a perspetiva de Foucault (1997), o correlativo ou o elemento fulcral produzido no exercício de 'saber - poder' sobre o corpo. Se a alma é o 'depositante' de verdades e discursos, o corpo seria o 'depositário' de marcas, símbolos e sinais, que nele se inscrevem, provenientes do influxo relacional com o mundo. (MERLEAU-PONTY, 1997, p. 23-58). De fato, o corpo seria a 'superfície de inscrição', constituindo o universo no qual se inscreve os valores, as representações, os significados e os comportamentos/ atitudes do ser humano. Trata-se de uma espécie de 'escrita viva ou vivificante', em que se imprimem as ressonâncias percetivas e se escavam os trilhos, com os seus sentidos, na existência humana. (WENGER, 2001, p. 21-37).

Sabemos que o corpo é afetado pelos intercâmbios e mudanças da realidade, transformando-se lentamente (envelhecimento) ou é transformado intencionalmente (cultura do corpo), respondendo às diferentes estratégias adotadas pelo homem na vida, na ação e pensamento, levando a bom porto os respetivos planos de (auto)realização. (FEHER; NADDAFF; TAZI, 1990, p. 11-13). Estas mudanças experimentadas, cada vez mais reais, atuam, por vezes, como obstáculo à inteligência ou são o trampolim de uma entidade autónoma, ou, ainda, aparecem como expressões. A relação entre o corpo (matéria) e a alma/espírito e do corpo e a mente frágua num 'Eu nas suas circunstâncias' de vida, expressando uma imagem do mundo projetada por um espelho ou reflexo do espírito. É óbvio que o corpo, na sua perspetiva existencial e educativa, 
relaciona-se com a corporeidade e o organismo. De tal modo que na 'História do Corpo Humano’ ele não é tanto a história das suas representações, mas sim a narração ou narratividade (terminologia de Ricoeur) dos seus modos de construção. Esta história das imagens e das representações referentes ao corpo real, à sua beleza (arte grega) e/ou seu culto, leva-nos a considerá-lo como uma entidade 'sem história', já que se trata do organismo (ciências naturais), ou do corpo entendido pela fenomenologia, sociologia e pedagogia (educação estética), ou do corpo instintivo e reprimido, como objeto de estudo da psicanálise (psicologia). (FEHER; NADDAFF; TAZI, 1990, p. 33-48).

$\mathrm{Na}$ verdade, a história desses modos de construção pode transformar o corpo, evitando os excessos entre a ciência e a ideologia, autenticidade e alienação entre a ciência e a ética. É nesta 'densa perceção do presente', no dizer de Foucault (1997), que construímos o corpo para nós próprios. Se compararmos as construções primitivas com as perceções dos nossos corpos hoje em dia, estudando as transformações relacionadas com as técnicas do corpo e os novos problemas que eles contêm, podemos estabelecer as fronteiras atuais que limitam uma ética 'do' ou 'para' o corpo. (DOWNING, 1995, p. 21-39). Esta dimensão ética vai mais além da simples determinação dos valores que melhor protegem o corpo contra as doenças, as epidemias ou as transformações causadas pelos desejos carnais e o narcisismo de beleza, contra o crescimento da confusão entre o homem e a máquina, ou a dissolução entre a procriação e a sexualidade. (PERA, 2006).

Numa tríade de pontos abordaremos hermenêuticamente: o 'corpo' versus 'corporeidade' na visão filosófico-pedagógica; a 'corporeidade' em Merleau-Ponty e Zubiri; a relação corporeidade e aprendizagem no plano educativo e/ ou pedagógico, no contexto do pensamento atual (teoria da complexidade). Reconhecemos que todo o movimento humano se expressa pela sua própria cultura, que é o património dos grupos sociais, das formas de ser, atuar e entender o mundo.

\section{Corpo versus corporeidade no discurso filosófico-pedagógico}

A questão da corporeidade na filosofia do corpo ao longo da História faz-nos mergulhar no movimento do corpo, desde a perspetiva de diferentes pensadores e conceções. Ao embrenhar-nos nessas conceções, temos o intuito de descobrir 'como' e 'por que' o corpo foi na antiguidade visto como 'objeto' e a valorização dos seus aspetos, na complexidade do ser humano. As conceções 
mais antigas de corpo consideram-no como um 'instrumento da alma'. Neste sentido, o corpo é o túmulo ou prisão da alma platónica. Esta visão instrumentalista do corpo está presente: em Aristóteles, que vislumbrava o corpo como 'realidade limitada'; em Epicuro, com o seu materialismo, que não implicava a 'negação da substantividade da alma', assemelhando-se aos estoicos (a alma é que domina o corpo); e, até, em Hobbes (2010), em que o espírito não é senão um movimento em certas partes do corpo.

Na Grécia a conceção do 'microcosmos' emancipa-se para o 'macrocosmos', em que a natureza condicionava e influenciava a visão do corpo. Platão, ao refletir sobre o mundo das ideias, considera a alma encarcerada no corpo, constituindo o mundo real. $\mathrm{O}$ corpo era apresentado como uma dimensão inferior, limitado e contraposto à alma (perfeita, eterna e imutável), lançando os pressupostos da teologia cristã. Todas as atividades do intelecto consideravam-se na perspetiva platónica, como 'nobres', fomentando o 'ócio prestigioso' $\mathrm{e}$, relegando às classes inferiores, os trabalhos manuais ou braçais. (LOWEN, 1995). Por sua vez, Aristóteles, ao desprezar o trabalho físico exercido pelo corpo, considera-o como coisas de escravos, empenhando-se mais na questão racional e não tanto nos impulsos e desejos inconscientes. A ideia do Estagirita, da alma ter a forma do corpo (hilemorfismo), influenciou o empirismo, que admitia que o corpo ('physis') interage com o mundo, a partir das perceções sensoriais (sentidos, intuição, consciência ou 'psique'). Esta corrente marcou a modernidade. (DUCH; MÈLICH, 2005, p. 127-143).

A perspetiva instrumentalista de que o corpo não existe sem a alma e vice-versa predominou em toda a filosofia medieval e só se alterou com o dualismo cartesiano, de que a alma e corpo são duas substâncias diferentes (o corpo como máquina) (Descartes). Esta teoria serviu de referência para vários estudos sobre os corpos vivos. O pensamento cartesiano instaura a fragmentação da perceção corpórea ('penso, logo existo'), determinando duas 'instâncias do corpo': a res extensa (corpo e matéria) e a res cogitans (coisa pensante). Este dualismo psicofísico orientará várias outras abordagens distintas da holística dos gregos. (LOWEN, 1995, p. 63-78).

$\mathrm{Na}$ época moderna o homem passou a ser visto como uma máquina de 'produção' que incentivava o individualismo, fruto da revolução científica, o que obrigou a 'Ciência' a dividir-se para poder compreender o mundo. O ser humano deixou de ser uma dimensão da totalidade (separação entre ser humano e natureza) e com as transformações sociais surgiu o individualismo como expressão ideológica (capitalismo industrial), sendo a perceção da alma a sua fonte energética. O corpo passa a ser 'objeto de trabalho'. Ele devia estar em constante movimento para ser valorizado (objeto). (ORTEGA, 2008; PERA, 2006). 
$\mathrm{Na}$ verdade, intentou-se explicar teoricamente a existência humana, na base da 'Deusa Razão', valorizando a 'mente' e desprezando o 'corpo'. O próprio Rousseau alertou para a importância da educação do corpo na obra 'Emílio' (educação sensorial), considerando essa valorização como uma parte do conhecimento. Esta ideia seria retomada por Kant, que afirmou que todo o conhecimento precisava ser comparado com o anterior, para poder construir-se de novo. Começava-se, assim, a conhecer o corpo através da fenomenologia. A sintonia entre 'corporeidade - prazer - jogo' era uma fenomenologia que unia a 'consciência' e a 'mente'. No ser humano a corporeidade é que nos permite 'ser' e 'estar no mundo'. (MERLEAU-PONTY, 2006).

A filosofia moderna e contemporânea desenvolveu algumas respostas para aquela problemática. Uma delas considerava o corpo como espírito (conceito utilizado por Leibniz), concebendo o 'corpo vivo' como substância espiritual agrupado à volta de uma 'entelequia dominante'; outra resposta refere-se a Platão e a Hegel, que afirmam que o corpo é uma manifestação ou realização externa da alma, permanecendo esta conceção nas doutrinas que consideram o corpo como um complexo de fenómenos expressivos. Uma outra resposta nega a diferença de 'substâncias', sendo a alma e o corpo manifestações únicas, de tal modo que Espinosa sustentava que a mente e o corpo formam um só e mesmo indivíduo (atributo do pensamento). E, uma outra resposta considerava o corpo como concretização das nossas vivências (fenomenologia de Husserl, Merleau-Ponty, etc.). (MACHADO, 2010, p. 83-86). Todas essas conceções contribuíram para essa complexidade que foi a questão do corpo na sociedade moderna (linguagem e/ou expressão corporal). Simultaneamente, o darwinismo secularizou o corpo, demonstrando que ele é um produto da evolução biológica, impregnada pelo contexto físico-geográfico e histórico em que se situa.

Esse relegar do corpo para um segundo plano do discurso filosófico da modernidade não evitou que alguns autores ou perspetivas teóricas lhe conferissem outro estatuto ou dignidade ontológica (Merleau-Ponty, Nietzsche, Adorno, Deleuze, etc.). Um desses exemplos é o de Sartre, na obra "O Ser e o Nada", numa vertente de ontologia fenomenológica, ao tratar o corpo em três dimensões ontológicas: o corpo como 'ser-para-si' (a 'facticidade') - corpo concreto na sua articulação com a consciência; o 'corpo-para-outro' numa situação dada, numa conexão em que o 'Eu' deve captar o próximo como aquele para quem existe como objeto; e o corpo como dimensão ontológica, enquanto se é para o 'outro', revelando-se sujeito para o qual se é objeto - 'eu personalizado', numa relação com o próximo conhecido pelo 'outro' em facticidade, a título de ser corpo. (ORTEGA, 2008, p. 49-61). Sartre objetiva o corpo humano implicado na consciência e vice-versa, de modo que só o encontramos como corpo e 
consciência no plano concreto. Só pela abstração podemos separar 'corpo e consciência'. (DUCH; MÈLICH, 2005, p. 45-72).

Na sociedade atual, imbuída pela lógica de mercado, da mundialização e globalização, impôs-se o padrão de corpo 'perfeito', atlético, desenvolvendo hábitos e comportamentos que perseguem a 'beleza física', muito ajudado pela publicidade e mídia, em que o valor dado ao corpo se relaciona como uma mercancia, que deve ser cuidada. O próprio Foucault (1997) destacará o corpo como expressão de poderes e de saberes, que se articulam estrategicamente na história da sociedade ocidental. Ou seja, o corpo como agente e peça num jogo de forças presente nas redes sociais converte-o em depositário de marcas e sinais, que nele se inscrevem, e em que a corporeidade se converte no seu 'campo de prova'. Por isso, a corporeidade nesta perspetiva filosófica parte da ideia de que o corpo é o sujeito da cultura - base existencial e não um objeto a ser estudado relativamente à cultura. Ao longo desses discursos filosófico-pedagógicos o corpo é o lugar de inscrição dos códigos ou dos signos, um tradutor ou descodificador/ permutador desses signos ou códigos, pois sozinho não significa nada (corpo inscrito 'de'), porque ele acarreta a cultura e a linguagem e, por consequência, um distanciamento da natureza. (ORTEGA, 2008, p. 23-44).

\section{A identidade e imagem como aspetos psicológicos do corpo}

Os estudos de Reich descobriram as patologias do corpo, elaborando uma terapia corpórea. Ou seja, ele pesquisou que a interrupção de uma experiência emocional produz bloqueios nos processos corpóreos específicos, mesmo não tendo consciência delas, nem da sua lembrança. Por isso, as repressões corpóreas convertem-se em tensões musculares que se vão estratificando e estruturando com o caráter. (VARELA, 1992, p. 14-38). No corpo há marcas visíveis na biografia vital afetiva da pessoa, tais como a dor, a raiva, a ira, o medo, o desespero, a angústia, a alegria ou a felicidade, etc., muitas vezes sem 'expressão', podendo causar, por falta dessas vivências, 'cicatrizes' ao nível afetivo-emocional (período da infância).

De fato, os bloqueios corpóreos, causados por aquelas interrupções, subjazem 'ativos', condicionando o sistema sensorial (modo de perceber), o sistema motor (movimento e ação) e até o sistema afetivo-emocional. São estas tensões musculares que determinam as modalidades de abertura do sujeito a novas experiências, por vezes dolorosas. Na verdade, a teoria de Reich alterou 
o modo de conceber, nos âmbitos da psicoterapia e da antropologia, a relação 'corpo - mente', possibilitando uma maior atenção pelo 'corpo' que, de diferentes modos, se encontra nos modelos da psicoterapia da década de 60 e 70 do século passado. Por exemplo, no contexto da 'New Age', deu-se uma atenção especial ao corpo, provocada por uma série de interpretações corpóreas, ao nível terapêutico ('energética vocal' de Coleman, 'grito primário' de Janov), do desenvolvimento humano (massagens, danças, técnicas de relax e meditação, etc.), da psicossomática, da neuroendocrinologia, técnicas de relaxamento muscular, da comunicação não verbal, etc. (LOWEN, 1995, p. 102-133).

$\mathrm{O}$ 'ground' referencial (metamodelos), dessas terapias, originou os seguintes enfoques: a visão holística da relação 'corpo - mente' ou 'mente corpórea' em Downing (1995); a importância do 'esquema corpóreo' (Schilder) naquilo que é 'corpo vivido' e o 'lugar' de patologias e terapias; a respiração (inspiração e expiração) e no relax representando a relação do organismo com o ambiente; e o corpo como o 'fundo da nossa identidade', em que brotam os desejos e se realizam experiências da nossa formação, dando ao corpo a capacidade de palavra e dando a palavra ao corpo. (DOWNING, 1995, p. 79-93). A psicologia intentou separar o corpo da mente, pensando que tudo tinha origem na 'psique', mas coube à psicologia humanista impulsar a importância do corpo, através da experiência e/ou vivência. Considerava-se que os corpos iam-se moldando, a partir de padrões provenientes da sociedade, provocando desequilíbrios no ser humano, pois se negava de alguma forma o nosso corpo e, simultaneamente, a experiência. (MATURANA, 1995). Ao tomar contato com o corpo abriam-se as possibilidades do seu uso. Possivelmente será, por isso, que as pessoas estão cada vez mais insatisfeitas com o aspeto corporal, sentindo-se retraídas consigo mesmas e recorrendo à cultura e imagem do 'corpo'.

Diz um epitáfio que há mais razão no corpo que na nossa melhor sabedoria. De fato, não é possível pensar no itinerário psíquico e pedagógico sem recorrer à reflexão e à experiência da corporeidade. Todas as consolidações que fazemos terão que ter em conta o saber psicológico e pedagógico. (GARCÍA CARRASCO; GARCÍA DEL DUJO, 2001, p. 36-78). É nessa compreensão psicopedagógica do corpo na educação, evidente nos processos educativos nos espaços escolares, que a escola inclui o ‘corpo’ (educação física, estética e ética) no processo formativo da corporeidade do educando, a partir do currículo, o qual contempla a vertente cognitiva e histórica, que o envolve nas emoções, nas representações e nas vivências, como elementos fulcrais. O conhecimento será o resultado dessa interpretação contínua, que emerge da capacidade de compreender o educando, originada nas estruturas do corpo, através das experiências de ação que vão pouco a pouco surgindo. (WENGER, 2001, p. 68-83). 


\section{A. Perspetiva da corporeidade em Merleau-Ponty e de Zubiri}

Trataremos de analisar no âmbito da fenomenologia hermenêutica: a perspetiva de Merleau Ponty (1993, 1997, 2006), destacando a intersubjetividade como experiência de existência configurada na corporeidade, ou seja, na experiência vivida, na visão do corpo e na relação deste com o 'outro'; e a perspetiva do filósofo espanhol Zubiri (1898-1983), em que o corpo é o mediador da nossa condição de ser na realidade, pois é com ele que nos situamos e pertencemos no tempo e no espaço, devido à atividade de apreensão sentiente da inteligência (estar-no-mundo).

\section{A.A. Teoria da corporeidade - o corpo em movimento em Merleau- -Ponty}

Merleau-Ponty norteia a sua abordagem para a conduta das expressões de vida, enquanto acontecimento. Destaca as estruturas do comportamento, numa perspetiva atomista e de estímulo físico e de contração muscular do corpo. Daí que o comportamento seja o exercício de corporeidade: "o espetáculo de uma consciência sob nosso olhar, o de um espírito que vem ao mundo". (MERLEAU-PONTY, 2006, p. 323). Esta postura do comportamento reducionista, diferente da mecanicista e psíquica, apresenta uma configuração para o exercício do pensamento expresso na vivência corpórea no mundo. De fato, cada organismo tem, na presença de um meio envolvente dado, as "suas condições ótimas de atividade, sua própria maneira de realizar o equilíbrio, e as determinantes interiores desse equilíbrio, que não são dadas por uma pluralidade de vetores, mas por uma atitude geral com relação ao mundo". (MERLEAU-PONTY, 2006, p. 232). Na verdade, o comportamento orienta-se às ações do corpo no mundo, já que faz parte do estar no mundo, e não é o resultado do reflexo e estímulos físicos. A sua existência tem significado nas ações no mundo.

Essa noção de comportamento é orientada às ações do corpo na sua presencialidade no mundo, não sendo um puro reflexo de estímulos físicos, já que faz parte desse mundo (existência significativa). Sabemos que a expressão do ser humano (imagem) é algo inerente ao seu comportamento, revelando o modo de ser desse comportamento. É verdade que Merleau-Ponty (2006, p. 230-233) não põe de lado os reflexos (condicionados), os fatores físico-sensoriais e biológicos, nem os estímulos, enquanto realidades desse comportamento humano. Contudo, crê que esses fatores limitam o sentido da ação no movimento do corpo e nas vivências que realiza. Ou seja, as relações do sujeito orgânico com o meio envolvente são relações dialéticas, que provocam novas relações não comparáveis a um sistema físico. (MERLEAU-PONTY, 1993, p. 54-67).

O ser humano percebe pelo comportamento a atividade nos seus níveis de potencialidade (criativa) e cria (capacidades) estruturas através da experiência 
vivida: o mundo percebido pela perceção da estrutura. São esses significados do mundo percebido que expressam realidades estruturais manifestadas na corporeidade. Pela sensibilidade do corpo o ser humano se efetiva no mundo, pela originalidade das suas experiências corporais, redescobrindo o mundo sensível. Esta forma de sensibilidade, apreendida pelos sentidos como expressão existencial, converte-se na vivência corpórea. O corpo esconde o que é o ser em si, na sua existência pessoal, como manifestação em situação, sendo no seu entendimento o espaço e luz (razão) para a perceção. (MERLEAU-PONTY, 2006, p. 228-230). De fato, o ato de ver materializa-se na realidade pela corporeidade, sem destituir a especificidade da visão. O espaço constitui o lugar do corpo, já que ele habita o espaço, qualificando-o, entrelaçando-se com a corporeidade. (MERLEAU-PONTY, 1997, p. 42-45). Este cálculo da espacialidade acontece na corporeidade do sujeito, constituindo-se numa inter-relação 'corpo - visão - realidade': fazer que o espaço e a luz se expressem. Isto é, o corpo sente a realidade, mas ao ser sujeito de perceção é um sentido da realidade.

Portanto, o corpo é para a alma o espaço e a matriz da sua existência. Merleau-Ponty (2006, p. 275-277), ao contrário de Descartes, interessa-se pelo movimento da 'corporeidade - mundo', analisando as especificidades da visão e do corpo (conexão viva). O mundo envolve o ser humano e também ele é envolvido pelo nosso corpo. Cabe à perceção desenvolver uma constante comunicação de vivências recíprocas 'corpo - mundo' (campo de perceção). Assim, na experiência corpórea, o olhar e o ver, duas conceções distintas, expressam o pensamento em ação, em movimento experiencial do vivido. Merleau-Ponty (1997, p. 15-18), ao escolher a visão e o corpo (experiências), evidencia o olhar inerente à corporeidade, pela experiência do pensamento como vivência dessa corporeidade (comportamento) e da historicidade constante da vida do sujeito. O desdobramento corporal dá-se no 'ser visto' e 'ser percebido' e 'percebendo', ou seja, nos laços da experiência do mundo vivido e do acontecer da corporeidade - mundo. (MERLEAU-PONTY, 1999, p. 227-229). Este ato é o próprio reconhecimento do corpo que revela dados sobre as coisas.

Por conseguinte, o corpo é o próprio espaço expressivo, que através da sua experiência alcança o mundo percebido, vivido, e é, como dizia Merleau-Ponty (1999, p. 275), pela "experiência percetiva me afundo na espessura do mundo". Com esta perspetiva supera o dualismo direcionado às consequências das atividades neuronais (representações mentais) e centraliza na fenomenologia a experiência do corpo ao atuar no mundo. As coisas constituem correlativos do corpo, sem se separar da pessoa que as perceba. Ou seja, o mundo fora de nós só é percetível pela experiência do 'Eu'. (MERLEAU-PONTY, 1999, p. 35-49). Deste modo, aquele pensador esboça uma forma de entender a perceção como uma forma de agir no mundo ou duma maneira de ser no mundo (cognição e 
perceção). (MACHADO, 2010, p. 87-89). Por exemplo, Maturana (1995, p. 102-105) entenderá a perceção como configuração da conduta, numa forma consensual entre o organismo e os elementos do mundo a que se encontra acoplado estruturalmente. Ou seja, produzimos um mundo de diferenças, através das mudanças de estados que experimentamos nesse acoplamento, produzindo uma série de coordenações de ações.

\section{A.B. Corporeidade e 'presencialidade física' em Zubiri}

Zubiri, numa abordagem antropológica ao 'homem e ao seu corpo', considera aquele como uma 'realidade única' de alma e corpo. Pretende com aquelas expressões designar a unidade da realidade humana. (ZUBIRI, 1982, p. 87-88). Assim, para entender a função que na realidade desempenha o corpo, aquele filósofo espanhol fá-lo analisando a realidade e a atividade humana. Para ele a realidade refere-se às 'coisas reais', que são sistemas de notas (propriedades, qualidades, partes constitutivas, etc.) de carácter substantivo. Ou seja, as coisas reais estão constituídas por notas 'de' (relação com outras notas, de forma independente), num momento fisicamente constitutivo. A unidade primária do 'de' ou 'nota de' é o sistema (construto da nota). Ora bem, estas notas constitucionais conferem a cada coisa real a sua estrutura física primária. O sistema cíclico de notas constitucionais constitui a substantividade, por isso, a realidade humana é a unidade de substantividade ou unidade física e primária de notas. (ZUBIRI, 1985, p. 78-91).

Zubiri (1981,p. 47-61) designa ao aspeto físico-químico da substantividade humana por 'organismo' e não por matéria, constituindo-se num subsistema parcial dentro do sistema total da substantividade, enquanto ao aspeto psíquico, que constitui a entidade dentro do corpo, prefere chamá-lo 'psique' e não 'alma' ou 'espírito'. Este último subsistema parcial tem caracteres irredutíveis ao subsistema orgânico, podendo, por vezes, ter um domínio sobre o outro subsistema. Antropologicamente o homem é uma substantividade psíquico-orgânica 'de', ou seja, a 'psique' é formal e constitutivo 'psique de' e o 'organismo' é formal e constitutivo 'organismo de'. (ZUBIRI, 1982, p. 91). Ambos momentos são subsistemas do sistema substantivo total (organização), que é a substantividade humana.

Nessa estruturação da realidade humana, aquele sistema apresenta três momentos fundamentais: a organização do sistema; a complexidade duma certa 'solidez', que é o momento da solidariedade (interdependente da organização); e a 'presencialidade física', que é o 'ter corpo' da substantividade psíquico-orgânica na organização solidária das suas notas. (ZUBIRI, 1986). Sendo assim, o corpo é a 'presencialidade física' da minha substantividade psíquico-orgânica na(s) realidade(s). E, é essa mesma substantividade no momento da 
'presencialidade física' na realidade que se designa por corporeidade (ZUBIRI, 1982, p. 93): momento estrutural da substantividade, com carácter abstrato de 'corpóreo' da realidade humana inteira.

O organismo físico-orgânico faz-se, 'desde si mesmo', formal e constitutivo corpóreo no sistema inteiro, consistindo na corporeidade 'de' a psique. Ora bem, esse 'de', da corporeidade transforma-a num momento estrutural da substantividade. Se o ser humano não organiza uma vida psíquico-orgânica solidária, não haveria corporeidade - atualidade física. Por isso, Zubiri (1986, p. 76-88) atribui qualidades à corporeidade, tais como: a expressão (fisionomia ou rasgos materiais do organismo); a 'presencialidade', que define o campo de realidade da substantividade psíquico-orgânica. Vida e corporeidade são momentos inseparáveis, mas distintos. O organismo tem caráter de corpo e de corporeidade, mas deve entender a corporeidade a partir da corporeidade do sistema e não ao inverso. (ZUBIRI, 1982, 1985). Ou seja, o organismo, a configuração das partes físicas e a corporeidade são aspetos das notas físico-químicas, que se entendem pelas características próprias do sistema: essas notas são 'organismo' pelo fato de serem momentos materiais de uma organização; são configurações de partes físicas por serem momentos de solidariedade do sistema; e são corporais ou somáticas, por serem momentos materiais da corporeidade (atualidade).

Por conseguinte, o sistema substantivo psíquico-orgânico, na realidade humana, compõe-se de três momentos estruturais: a organização, a solidariedade e a corporeidade. Trata-se de três momentos do sistema integral do ser humano, de momentos estruturais antropológicos e metafisicamente distintos entre si, da sua unidade de construto, em que cada um está fundado no anterior, ou seja, três momentos 'de' do sistema substantivo. O que se designa por 'corpo' tem funções distintas, fundadas cada uma na anterior (momentos), mas formalmente diferentes entre si: função organizadora, função configuradora e função somática. Esta última função, em rigor, é a que se refere ao corpo. Contudo, se não distinguimos as funções entre si, falaremos de 'organismo', que é um subsistema do sistema psíquico-orgânico total da substantividade, com aquelas três funções. (ZUBIRI, 1981). É desde a substantividade (organização das notas psíquico-orgânicas), que se entende tanto a psique como o organismo.

Por outro lado, haverá que evitar identificar o corpo (ou organismo) com o momento de corporeidade, que é próprio do sistema psíquico-orgânico inteiro. Por isso, a corporeidade é a atualidade presencial física ou o momento de atualidade de 'presencialidade' física na realidade. Cabe ao organismo ser o fundamento material dessa atualidade presencial. O homem para saber o que são as coisas reais possui a atividade ou ato da 'inteligência sentiente' (posição do sensível no ato intelectivo do ser humano), que executa a apreensão da realidade no ser humano. A expressão ou o modo da pessoa expressar-se é a 
consequência ou o princípio da corporeidade. Daí que educamos as expressões e a sua funcionalidade no corpo. (ZUBIRI, 1986, p. 105-127).

Em síntese, o corpo é uma estrutura 'de' uma matéria pré-corporal. Biologicamente o ser vivo é organismo (elementar) em que a matéria viva apresenta umas características que a identificam na sua estrutura funcional: matéria elementar (partículas elementares, incluindo a energia); matéria corporal - nova estruturação da matéria elementar; e matéria biológica, que é uma estruturação da matéria corporal. Esta última matéria resiste à dissipação e à positiva atividade de conservação, através da matéria viva e da matéria organizada. Todos estes tipos de matéria se apoiam mutuamente. A corporeidade implica o abstrato do corpóreo - um aspeto pertencente ao sistema psíquico-orgânico, em que o organismo físico-químico faz-se formal e constitutivo do corpóreo do sistema integral (corporeidade 'de' psique). (ZUBIRI, 1986). À medida que a corporeidade se organiza, se acopla às reações mais ou menos formalizadas e espontâneas, vai-se constituindo lentamente. É, por isso, que o homem é um animal de realidades, porque está inserido no corpo social, num sistema de possibilidades para si e para com os 'outros', que se estabiliza e se liberta para novos projetos, desde a sua substantividade (sistema de notas psíquicas, a psique, e corporais, o corpo).

\section{Educação e corporeidade na complexidade escolar}

A educação, no contexto de pós-modernidade, intenta instituir códigos morais que estabelecem condutas e reprimem as possibilidades de expressão do corpo, num distanciamento entre a aprendizagem e as vivências do sujeito. A corporeidade na aprendizagem implica uma compreensão na relação 'corpo - aprendizagem - cultura', através do diálogo epistemológico entre as ciências sociais e humanas ou ciências da educação. Em meados do século passado, a abordagem sistémica, principalmente ao nível da conceção biológica, faz que a natureza seja compreendida pela coexistência de 'organismo - ambiente', transformando as conceções, que acreditavam ser os genes os responsáveis pela transformação do ser vivo. Neste sentido, alguns biólogos propõem que o conceito de vida seja explicado pelo 'processo autopoiesis', ou seja, um organismo 'autopoiético' seria capaz de autogerir-se continuamente. (MATURANA; VARELA, 1995). Esta teoria da 'autopoiese' estuda os seres vivos a partir das suas relações com o ambiente envolvente.

Sabemos da implicação da teoria do 'logocentrismo' na educação e na abordagem ao trato do corpo e da corporeidade. Esta teoria foi desconstruída 
pela visão do pensamento complexo, ao indicar-nos novas perspetivas para a educação e para a construção de uma teoria da corporeidade aplicável no dia a dia educativo. (MORIN, 2004, p. 106-135). De fato, a educação refuta os determinismos e reconhece que o conhecimento provém do corpo a partir das nossas experiências vivas, entrelaçando as ações biológicas e os fenómenos sociais (aproximação concetual biológica e antropológica). Pensar o corpo na educação e na escola implica compreender que o corpo não é um instrumento das práticas educativas, já que as produções humanas (ler, escrever, contar, narrar, brincar, jogar, etc.) só são possíveis por sermos 'corpo'. Deve-se, pois, superar a instrumentalização e compreensão da corporeidade, como princípio epistemológico, capaz de dar novos significados à cognição e alterar as metas sociais e educativas. (LÓPEZ-IBOR; ALIÑO, 1974).

No processo educativo há três elementos fundamentais: a identidade do sujeito da educação (características próprias); a fisionomia (corpo - parte material); e o ambiente envolvente a cada um deles, no tempo e no espaço. Ou seja, a articulação do educando, com as suas características próprias (possibilidades e condições para se educar) com o ambiente, onde se educa ou aprende (espaço, contexto) e com o tempo instituído. A reflexão formativa e a análise ao destinatário na interação do ato de educar é a corporeidade, que é o produto integral da evolução do ser humano e constitui o âmbito básico da sua atividade mental.

Sabemos que a corporeidade indica a essência ou a natureza do corpo, isto é, integra tudo o que preenche o espaço e se movimenta e, simultaneamente, localiza o ser humano no mundo com o corpo, enquanto objetividade (matéria) e subjetividade (alma, espírito). (NANCY, 2007). Por este motivo, a corporeidade constitui-se nas seguintes dimensões educativas: física (estrutura orgânico-biofísica e motora); emocional-afetiva (instinto, pulsão, afeto); mental-espiritual (cognição, razão, pensamento, consciência); e sociocultural e histórica (valores, hábitos, sentidos, etc.). Parece, assim, definir-se como uma complexa dinâmica de auto-organização duma corporeidade viva, baseada no conhecimento 'do' e 'sobre' o corpo.

Vejamos alguns itinerários fundamentais na formação da corporeidade:

* - Educar numa visão integradora do 'corpo - alma'. No contexto social em que vivemos o corpo é uma parte instrumental de trabalho e prazer, em que a formação favorece o descobrimento da unidade inseparável do 'corpo - alma', isto é, o corpo como presença ('presencialidade') e como lugar de intersubjetividade.

* - Educar para a saúde - respiração, meditação e relax como elementos constitutivos da vida humana. Trata-se de aprender a cuidar da saúde e do corpo (educação corporal e física, higiénica) e de respirar, de modo a entrar nos níveis da nossa interioridade e modificarmos os nossos estados de consciência. É o com- 
promisso do ser humano com o mundo, cuidando-se de si mesmo, do seu corpo (parte física, higiénica), da alimentação e do seu bem-estar. A educação do corpo é uma aprendizagem formal, pois o ser que pensa é também o ser que age e sente, realizando-se e construindo-se na experiência vivida. A própria cognição emerge da corporeidade, expressando-se na perceção como movimento e, daí que se deva educar e compreender o corpo nas suas marcas sociais e históricas. Também, a corporeidade constitui num dos temas de reflexão para a educação física (ginástica).

* - Educar a 'corporeidade vivida'. Parece que se nega o corpo real e se enfatiza o 'corpo visivo'. Todo o processo educativo deve favorecer a experiência interna da reapropriação do corpo como lugar da própria vitalidade (identidade). É através da formação da corporeidade que descobrimos a beleza vibrante do corpo, nos libertamos das tensões e medos, damos harmonia aos movimentos, valorizamos as nossas ações (valores) e compreendemos e vivemos as nossas experiências ou vivências. (MILSTEIN; MÉNDEZ, 2009, p. 22-45; PERA, 2006, p. 23-59).

Por conseguinte, o pensamento complexo das coisas, da vida e do mundo permite compreender que a corporeidade exige uma abertura, que está para além dos modelos filosóficos dos anteriores paradigmas de análise, os quais se sustentavam na conceção grega da dicotomia entre 'corpo e alma'. (MORIN, 2004). Neste sentido, a corporeidade humana constitui-se numa emergência do processo de evolução que conduziu a 'physis', o ‘bios' e a esfera antropológica e social a essa complexidade dos sistemas e das organizações. As representações do corpo estão cada vez mais multifacetadas e fragmentadas, convertendo-se num 'corpo da mídia', do 'corpo-estético', do 'corpo-manequim', do 'corpo-instrumento', etc., ou seja, num corpo - produto e/ou corpo-mercadoria. (VINCENT, 2004, p. 55-67).

É nossa opinião, seguindo Zubiri $(1985,1986)$, que devemos resgatar a questão do corpo nas práticas pedagógicas, como um processo dinâmico que entrelace os diferentes saberes, destacando os contributos das teorias da ação comunicativa (Habermas) e da complexidade, orientado a uma ação interdisciplinar que facilite a compreensão das qualidades e dimensões pertencentes ao ser humano enraizadas no corpo. É, pois, através do corpo, que identificamos a nossa individualidade, existência e o próprio Ser. (ASSMANN, 1994; DUCH; MÈLICH, 2005).

\section{Questões finais (IN) conclusivas}

O corpo, analisado na perspetiva filosófica, anatómica, fisiológica, médica, artista, etc., é contemplado como objeto do mundo exterior (a parte da coisa que 
temos). É sabido que os movimentos expressam de alguma maneira a forma de ser do ser humano e como se aproxima ao 'outro(s)'. Ao negarmos o corpo negamos a nossa identidade e, por isso, na sociedade atual gera-se uma crise nas pessoas, por não se reconhecerem a si mesmas e por quererem mudar de forma corporal. De fato, a sociedade estabelece, pelos meios de comunicação social e 'Internet', padrões para os que não estão contentes com o seu corpo. Estes meios incitam à fama e ao privilégio de se ter um corpo modelo, atlético e esbelto, sem compreenderem o ser humano em si e a fenomenologia da sua vida. (MERLEAU-PONTY, 1999). Este surgimento do 'corporeísmo', termo proposto por Maisonneuve para designar a evolução das atitudes, das representações sociais, dos afetos e das ideologias relacionadas com o corpo, constituiu uma forma discursiva e prática de conferir ao corpo uma dada atenção e um valor de privilégio (hedonismo). (GODARD, 2005; NANCY, 2007).

O corpo fala por si através de diversas expressões ou manifestações, que não são percebidas antropologicamente, no poder da linguagem que expressa. Pelo corpo alcançamos uma conceção global de homem ou de mulher, permitindo ser um ponto de referência e de relação. (BRETON, 1990). É pela linguagem corporal que conseguimos a comunicação, revelamos a nossa personalidade, a cultura e a sociedade a que pertencemos. Ou seja, pelo corpo a cultura capta os seus limites de ordem psicobiológica e social. Essas manifestações corporais indicam maneiras de ser com sentido de algo importante para quem as expressa (movimento do corpo). Daí que o corpo constituía a nossa identidade (imagem), pois, sem ele, nada seríamos no mundo. (GARCÍA CARRASCO; GARCÍA DEL DUJO, 2001, p. 163-165; LÓPEZ-IBOR; ALIÑO, 1974, p. 36-48).

Em relação à corporeidade ela necessita ser aprendida e deve significar um desafio para a imaginação e criatividade. Por isso, o esforço de compreensão antropológica da corporeidade é pista para a prática educativa. A qualidade de vida de cada um de nós depende da forma com que assumimos a corporeidade, da maneira em que respondemos ou nos revoltamos contra ela, mediante o acesso ao mundo ou à realidade envolvente. Todo o processo de formação se mediatiza pelas diferentes formas de explicitação da corporeidade, de tal maneira que os educadores iniciam as suas primeiras ações educativas com atividades de implicação corporal e expressiva (exercícios de psicomotricidade e psíquico-sensoriais). (GARCÍA CARRASCO; GARCÍA DEL DUJO, 2001, p. 180-186). Um dos objetivos nucleares da formação será explicitar a importância do corpo na qualidade significante, no seu valor expressivo e no controle consciente do papel significante da expressão corporal, apoiando-se na arte da dramatização e na possibilidade de viver (drama da vida), ou seja, na dinâmica de interação social entre as pessoas, nos gestos de concordância e na veracidade da comuni- 
cação, numa desconstrução e reconstrução da imagem corporal para uma nova consciência da corporeidade. (ASSMANN, 1994, p. 34-59).

De fato, o mesmo se passa com a educação, quando o conhecimento ou os saberes e a experiência adquirida sobre o corpo constitui uma área de formação básica (escolar). A fenomenologia indica-nos que o corpo é o mediador da nossa condição de ser no mundo, pois graças a ele situamo-nos e pertencemos a um tempo e espaço, conseguido através da atividade de apreensão 'sentiente' de realidade na terminologia de Zubiri (1986), bem expressa nas suas categorias (visual, auditiva, olfativa, gustativa, tátil, etc.), permitindo ao ser humano a diferenciação e discriminação das sensações, dos elementos comunicacionais, da valorização sociocultural, das consequências sociais da interação, etc. Tudo isto demonstra que o corpo se constitui como uma construção simbólica dependente dos estados das coisas, da visão do mundo e do próprio autoconceito como pessoa. É claro que o meio envolvente passa a ser interpretado como um sistema permanente de comunicação corporal, que transfere informação não verbal e que obriga o sujeito a ter comportamentos mais ou menos conscientes. $\mathrm{Na}$ verdade, essa historiografia experiencial-emocional de transação do corpo humano com o meio constitui o tradutor e acumulador dos sinais que dele recebe. Isto é tão evidente que algumas características do meio cultural valorizam aspetos da corporeidade, por exemplo, a apologia ou culto do corpo e o vigor atlético e corporal, a genitalização do 'eros', o romanticismo cultural e outras formas espontâneas orgânicas. (BRETON, 1990, p. 73-79; PERA, 2006, p. 3348). Nasce assim a cultura e a mercantilização da corporeidade.

Em síntese, a apreciação entre corpo e corporeidade não é apenas uma realidade biológica, mas sim uma construção cultural e histórica que ultrapassa os dualismos 'corpo - alma' e 'corpo - mente'. O corpo acarreta temporalidades e territórios identitários que funcionam como símbolo cultural para através dele distinguir, agrupar, classificar e ordenar, numa sensibilidade e expressão criativa. Sendo assim, o seu correlato, a corporeidade concebe o corpo como movimento, associando-se à motricidade, à perceção, à linguagem, à sexualidade, aos mitos, à experiência vivida, à poesia do sensível como fenómeno complexo.

\section{REFERÊNCIAS}

ASSMANN, H. Paradigmas educacionais e corporeidade. 2. ed. Piracicaba, SP: UNIMEP, 1994. 
BRETON, D. Le. Anthropologies du corps et modernité. Paris: PUF, 1990.

DOWNING, G. Il corpo e la parola. Roma: Astrolabio, 1995.

DUCH, L.; MÈLICH, J. C. Escenarios de la corporeidad. Antropología de la vida cotidiana (2/1). Madrid: Trotta, 2005.

FEHER, M.; NADDAFF, R.; TAZI, N. (Eds.). Fragmentos para una Historia del Cuerpo Humano. Parte Primeira. Madrid: Taurus, 1990.

FOUCAULT, M. Arqueologia do saber. 5. ed. Rio de Janeiro: Forense Universitária, 1997.

GARCÍA CARRASCO, J.; GARCÍA DEL DUJO, A. Teoría de la Educación. Tomo II: Procesos primarios de formación del pensamiento y la acción. Salamanca: Ediciones Universidad de Salamanca, 2001.

GODARD, J.-Ch. (Dir.). Le corps. Paris: Vrin, 2005.

HOBBES, Th. El Cuerpo. Primera Sección de los elementos de filosofía. [De Corpore. Elementorum Philosophiae. Sectio Prima]. Valencia: PreTextos-Filosofia Clásica, 2010.

LÓPEZ-IBOR, J. J.; ALIÑO, J. J. L. F. El cuerpo y la corporeidad. Madrid: Gredos, 1974.

LOWEN, A. Arrendersi al corpo. Roma: Astrolabio, 1995.

MACHADO, B. F. G. Visão e corporeidade em Merleau-Ponty. Argumentos - Revista de Filosofia, Ano 2, n. 3, p. 82-88, 2010.

MATURANA, H. R. Da Biologia à Psicologia. Porto Alegre: Artmed, 1995.

MATURANA, H.; VARELA, F. A árvore do conhecimento: as bases biológicas do entendimento humano. Tradução de: Jonas Pereira dos Santos. Campinas, SP: Ed. Psy II, 1995.

MERLEAU-PONTY, M. Elogio da filosofia. Lisboa: Guimarães Editora, 1993.

MERLEAU-PONTY, M. O olho e o espírito. 2. ed. Lisboa: Veja, 1997.

MERLEAU-PONTY, M. Fenomenologia da percepção. São Paulo: Martins Fontes, 1999.

MERLEAU-PONTY, M. A estrutura do comportamento. São Paulo: Martins Fontes, 2006.

MILSTEIN, D.; MÉNDES, H. La escuela en el cuerpo. Buenos Aires: Miño Dávila, 2009.

MORIN, E. Religando fronteiras. Passo Fundo, RS: Edições UPF, 2004.

NANCY, J. L. 58 indicios sobre el cuerpo. Extensión del alma. Buenos Aires: La Cebra, 2007.

ORTEGA, F. F. O corpo incerto: corporeidade, tecnologias médicas e cultura contemporânea. Rio de Janeiro: Garamond, 2008.

PERA, C. Pensar desde el cuerpo: ensayo sobre la corporeidad humana. Madrid: Triacastela, 2006. 
VARELA, F. De cuerpo presente. Las ciencias cognitivas y la experiencia humana. Barcelona: Gedisa, 1992.

VINCENT, G. (Dir.). Le corps, le sensible et le sens. Strasbourg: Presses Universitaires de Strasbourg, 2004.

WENGER, E. Comunidades de práctica. Aprendizaje, significado e identidad. Barcelona: Paidós, 2001.

ZUBIRI, X. Naturaleza, Historia, Dios. 8. ed. Madrid: Editora Nacional, 1981.

ZUBIRI, X. Siete ensayos de antropología filosófica. Bogotá: Publ. Universidad de Santo Tomás - Centro de Enseñanza Desescolarizada, 1982.

ZUBIRI, X. El Hombre y Dios. Madrid: Alianza Editoral, 1985.

ZUBIRI, X. Sobre el Hombre. Madrid: Alianza Editoral, 1986.

Texto recebido em 19 de abril de 2015. Texto aprovado em 18 de junho de 2015. 